\title{
Accomplishment of water safety plan using quality assurance tool in 2020-2021: A case study in a western city of Gilan province, Iran
}

\author{
Rahim Aali $^{\circledR}$, Mohammad Fahiminia $^{{ }^{\circledR}}$, Mahdi Asadi-Ghalhari $^{{ }^{\circledR}}$, Farzaneh Fanaei $^{{ }^{\circledR}}$, Roqiyeh $^{\text {Mostafaloo }^{2}}{ }^{\circledR}$, \\ Amin Kishipour ${ }^{1,2^{*}}$
}

${ }^{1}$ Department of Environmental Health Engineering, Cellular and Molecular Research Center, Qom University of Medical Sciences, Qom, Iran

${ }^{2}$ Department of Environmental Health Engineering, School of Health, Qom University of Medical Sciences, Qom, Iran ${ }^{3}$ Social Determinants of Health Research Center, Faculty of Heath, Birjand University of Medical Sciences, Birjand, Iran

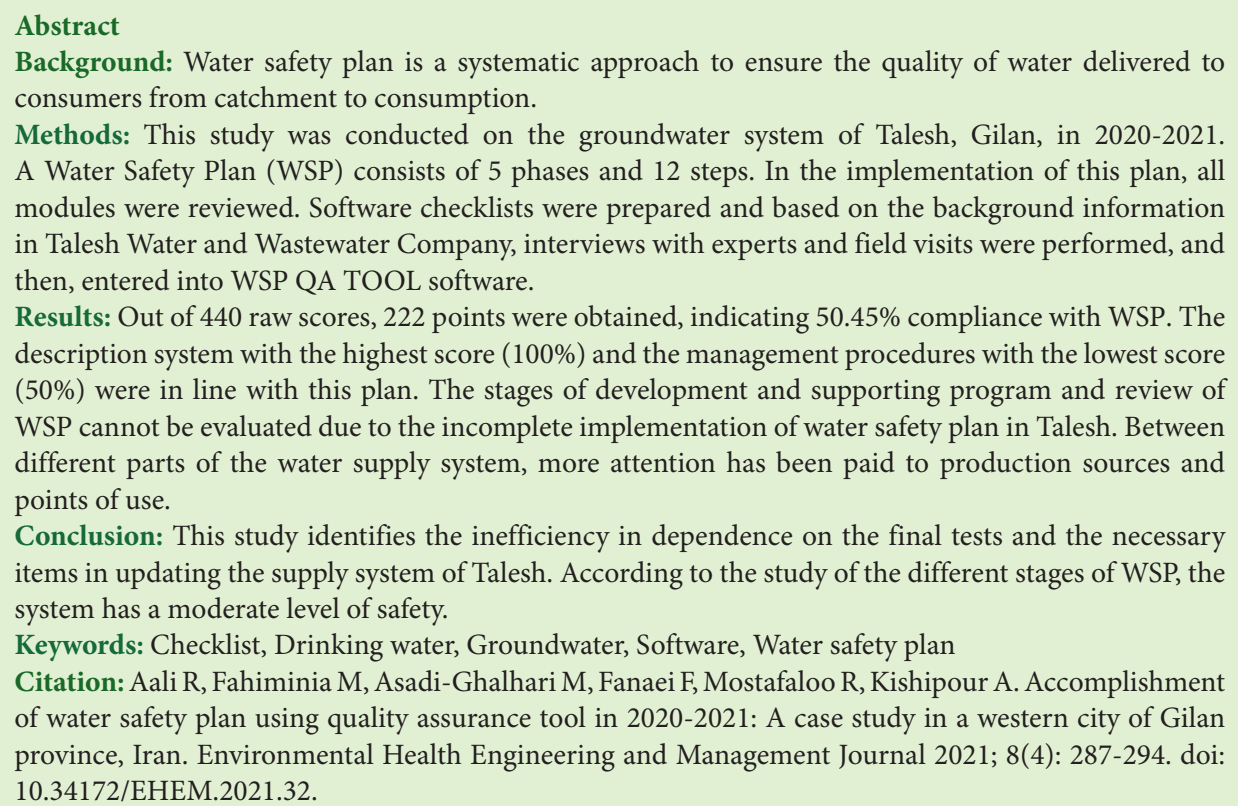

\section{Introduction}

Providing safe drinking water in developing countries is essential for survival $(1,2)$. Therefore, sufficient, safe, and accessible water is the right of all human beings (3). Lack of safe drinking water can cause a variety of diseases (4). The introduction of various chemicals into drinking water following the advancement of science and technology in the twentieth century was one of the important reasons for the transmission of waterborne diseases $(5,6)$. The presence of chemical compounds in water such as nitrate, nitrite, fluoride, and lead was the cause of 34 diseases in the United States, according to the report of Centers for Disease Control and Prevention $(7,8)$. Ten percent of the world's under-five mortality is due to diarrhea (6).

Therefore, due to the importance of having access to safe drinking water in the daily life of every human being, it is one of the goals of sustainable development of all societies until 2030 (3). In order to make sure the safety of drinking water in Stockholm in 2001, a framework consisting of goals based on health, water safety plan and guidelines relative to the quality of drinking water was presented $(9,10)$. Subsequently, the World Health Organization (WHO) introduced the Water Safety Plan (WSP) in 2004, which marked the largest change in global attitudes about how water resources are managed $(11,12)$.

One of the goals of the WSP is to manage the supply of safe drinking water from the source of production to the point of consumption (13). The WSP has been performed in various parts of the world (93 countries) and is being developed in 69 other countries as a policy 
or regulatory requirement $(12,14)$. In Iceland, after the implementation of the plan, a significant reduction in diarrheal diseases was observed (15). Uganda launched a WSP earlier than any other country on the African continent (13). Isfahan's drinking water supply system in Iran as a pilot in 2011 implemented a water safety plan (14). The main aim of WSP is to prevent contamination of raw water sources, to eliminate water contamination by treatment, and to prevent secondary contamination during storage, distribution, and use (16-19). That is the reason for the superiority of this plan over traditional methods of water quality assessment. In the traditional method, the process of sampling and analysis of results is time consuming and always reports past water quality and cannot predict the occurrence of accidents in the water supply system to minimize risks $(12,20)$. While WSP has a preventive management approach that includes three main components: Health goals, a water secure program, and an independent supervision system (20,21-23).

In order to evaluate the various stages of water safety plan implementation, in 2010, the WHO and the International Water Association (IWA) introduced a software called Water Safety Plan Quality Assurance Tool that includes 5 phases of 12 stages (Table 1), which seems to be not used in many countries due to the novelty of this software. This software has a powerful tool in identifying the stability and infirmity of each step of the WSP and it was used in the present study (24-26). Therefore, the aim of this study was to appraise the implementation of water safety plan, specify the stability and infirmity in each stage of the drinking water supply system, and determine the areas required for upgrading in water supply systems in Talesh. This study was suggested to identify the weaknesses and preventable points in the water supply system of Talesh, and highlight the need to change the existing attitude and the value of WSP in increasing the drinking water quality index. In addition, considering potential risks, appropriate solutions to reduce these risks in urban water supply systems will help (27).

\section{Materials and Methods}

This study was conducted on the water supply system in Talesh in 2020-2021. Talesh is one of the western cities of Gilan province located in the north of Iran with an area of $1427 \mathrm{~km}^{2}$ and a quarter of the province and a population of 59156 people in 2019. Figure 1 shows the location of Talesh on the map. The city is geographically located with a length of 48.906337 degrees, latitude 37.796390 degrees, and altitude 56 meters above sea level. The city uses groundwater resources for drinking water. Currently, 15 deep wells with a flow rate of $20736 \mathrm{~m}^{3} / \mathrm{s}$ are used to supply drinking water. The length of the water transmission line of this city is $14.5 \mathrm{~km}$ and the length of the water distribution network is $138 \mathrm{~km}$. $24.65 \%$ of the water of these sources is removed from the consumption cycle due to being thrown out.

The WSP is a systematic guide to prevent water pollution with the purpose of provided safe drinking

Table 1. Different stages of water safety plan

\begin{tabular}{|c|c|}
\hline Stages & Description of Steps \\
\hline WSP team & $\begin{array}{l}\text { This team consists of experienced and specialized people in the field of water extraction, treatment and distribution, as well as } \\
\text { familiarity with potential hazards from supply sources to the point of consumption. }\end{array}$ \\
\hline System description & $\begin{array}{l}\text { All four parts of supply sources, treatment plant, transmission and storage system and distribution and consumption of water } \\
\text { supply system are studied. The aim of this study is to make sure that the quality index of raw water and treated water was } \\
\text { documented, which enables adequate risk management and assessment. }\end{array}$ \\
\hline $\begin{array}{l}\text { Hazard identification and } \\
\text { risk assessment }\end{array}$ & $\begin{array}{l}\text { Hazards (physical, chemical, biological) and hazardous accidents are identified in catchments, treatment plant, reservoirs, } \\
\text { distribution systems, and points of use. Risks are scored and prioritized based on the matrix. }\end{array}$ \\
\hline $\begin{array}{l}\text { Control and validation } \\
\text { measures }\end{array}$ & $\begin{array}{l}\text { At the same time as identifying hazard and assessing risk, the WSP team should propose risk mitigation measures through } \\
\text { field observations, characteristics of water produced, or monitoring of data. The effectiveness of each control criterion must be } \\
\text { determined by its position in the water supply process, which is called validation. }\end{array}$ \\
\hline $\begin{array}{l}\text { Development of } \\
\text { improvement plan }\end{array}$ & $\begin{array}{l}\text { Risks that have been identified in the prior stages and the current control measures have not reduced their amount or do not } \\
\text { exist at all, require a short-, medium- or long-term recovery plan. }\end{array}$ \\
\hline Operational monitoring & $\begin{array}{l}\text { Objectives of the operation monitoring program; validation, proof of efficiency, and proof of continuity of operation are all } \\
\text { control measures based on the field and computational observations. }\end{array}$ \\
\hline WSP validation & $\begin{array}{l}\text { Processes indoor and outside audits and consumer consent assessments ensure that the system has the ability to continuously } \\
\text { deliver high quality water in order to meet health-oriented goals. }\end{array}$ \\
\hline Management instructions & $\begin{array}{l}\text { The types of operating methods that are in operation under normal conditions and the occurrence of system crashes, are the } \\
\text { main components of WSP. These instructions should be prepared by experienced staff and should be updated if necessary. }\end{array}$ \\
\hline $\begin{array}{l}\text { Development of support } \\
\text { programs }\end{array}$ & $\begin{array}{l}\text { Support programs are activities that will lead to the increase of human knowledge and skills, obligation to the implementation } \\
\text { of the water safety plan, and increase in the management capacity of the system for safe water delivery. }\end{array}$ \\
\hline WSP review & In addition to periodic review, the safety plan team reviews the period by analyzing the collected data. \\
\hline $\begin{array}{l}\text { WSP investigation } \\
\text { following an accident }\end{array}$ & $\begin{array}{l}\text { In order to investigate and identify new hazards, hazardous events or failure of control measures, the water safety program is } \\
\text { reviewed after emergencies. }\end{array}$ \\
\hline
\end{tabular}




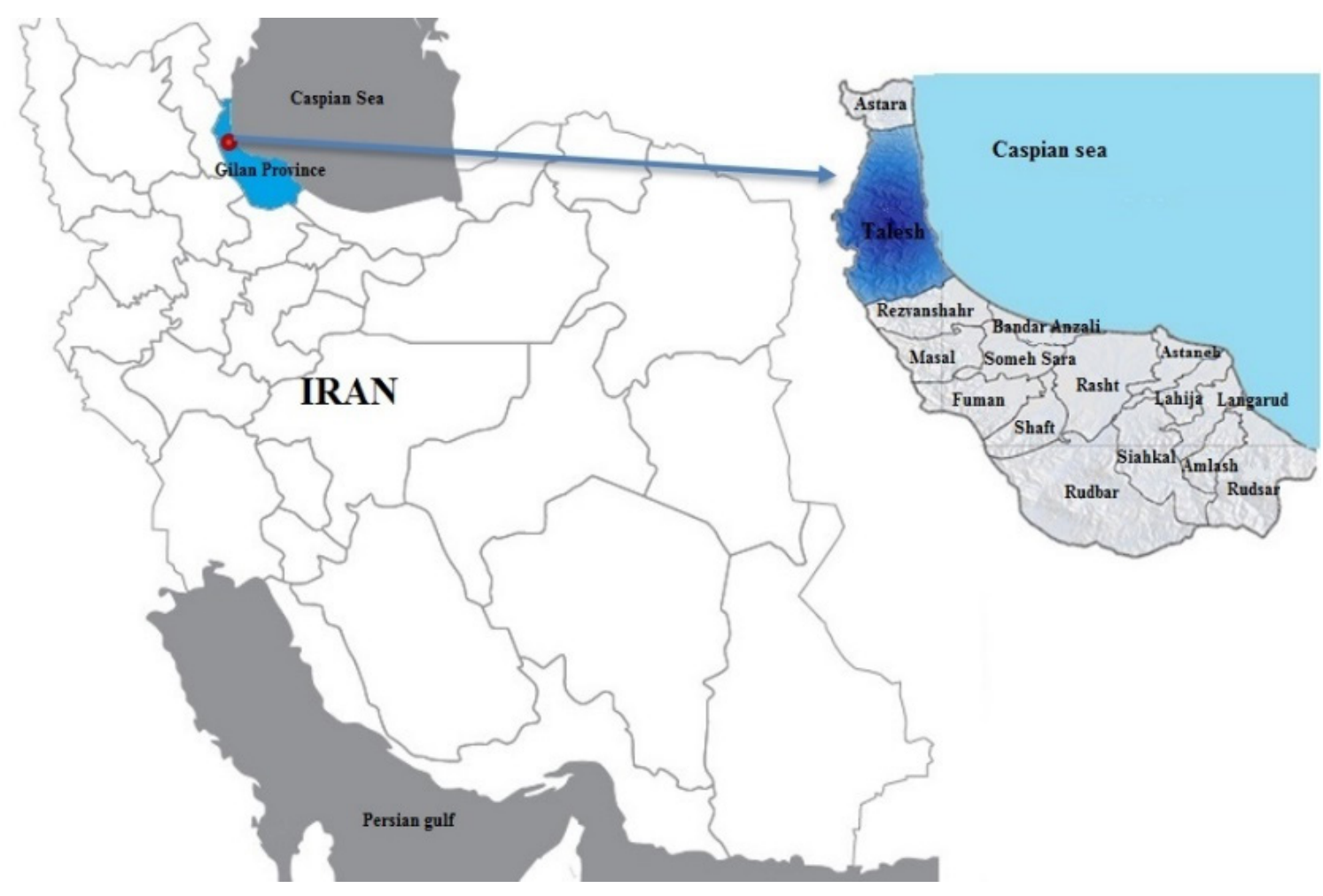

Figure 1. Geographical location of Talesh in Iran.

water that increase consumer confidence. This plan is a powerful tool for preventive measures and ensuring the quality of drinking water, which uses assessment and risk management methods. In the early stages of water safety plan development, this tool can be used as a guide to evaluate how to implement the plan. In this study, this tool feature was used. Initially, quality assurance tools and checklists were developed. This checklist contains 85 questions in the form of 12 tables and is completed based on the information history of Talesh Water and Wastewater Company, interviews with experts, and field visits.

After completing the checklists, the answers given to each section are entered into WSP QA TOOL according to the instructions, and the results are displayed in the form of tables and graphs. The main part of the software was entered. The second part of the software is about the overview and instructions for using the tools and general structure of the software and who should use the tool, how and when data are entered quantitatively and qualitatively into the WSP QA TOOL. Therefore, in the third part, quantitative and qualitative data are entered in 12 tables based on the completed checklist. The tables consist of a number of specific topics, question options, and a guide to how to answer the questions. Answering a few questions should be continuous due to the relationship between them. When entering the answer to the checklist to the software, the scoring system is used according to the instructions. The software scoring method is a 5-point system ( 0 to 4 ). Table 2 shows how to score the questions.
The scores of Table 3 of the present study and the percentage of advancement in implementation for each stage are determined based on the relationships specified in the tool. The output of this tool can be viewed in WSP order at any time and will identify the points that need correction. The scores in this table are calculated from the following equations.

Possible raw score $=$ Number of question options $\times$ Maximum possible score for option (1)

Points earned $=$ Number of questions $\times$ Score (2)

Percentage of performance progress $=$ (Total points earned $\div$ Total possible raw score) (3)

Results

In this study, after entering the data, the data were analyzed using WSP QA TOOL, and the results are shown in tables and figures. These tables and figures will help the drinking water supplier of Talesh water supply system

Table 2. How to score the tool questions

\begin{tabular}{lc}
\hline Title & Score \\
\hline An action, process, or stage that has not yet begun. & 0 \\
\hline $\begin{array}{l}\text { An action, process, or step that its implementation has just } \\
\text { begun. }\end{array}$ & 1 \\
\hline $\begin{array}{l}\text { An action, process, or step that has been partially completed } \\
\text { and documented. }\end{array}$ & 2 \\
\hline $\begin{array}{l}\text { An action or process or step that has been substantially } \\
\text { completed and documented. }\end{array}$ & 3 \\
\hline $\begin{array}{l}\text { An action, process or step that is quite implemented and its } \\
\text { documentation is easily visible. }\end{array}$ & 4 \\
\hline
\end{tabular}


Table 3. Total evaluation of WSP stages and its results in Talesh water supply system in 2020-2021

\begin{tabular}{|c|c|c|c|}
\hline \multicolumn{4}{|c|}{ Overall progress according to the water safety plan (Tables $3-12$ ) in Talesh city } \\
\hline Table & Number of questions & Total possible score & Score $(\%$ executed $)$ \\
\hline Table 3- WSP team & 5 & 20 & $16 / 20(80 \%)$ \\
\hline Table 4- System description & 2 & 8 & $8 / 8(100 \%)$ \\
\hline Table 5- Hazard identification and risk assessment & 7 & 100 & $69 / 100(69 \%)$ \\
\hline Table 6- Control and validation measures & 5 & 68 & $39 / 68(57.35 \%)$ \\
\hline Table 7- Development of improvement plan & 3 & 48 & - \\
\hline Table 8- Operational monitoring & 4 & 64 & $35 / 64(54.69 \%)$ \\
\hline Table 9- WSP validation & 8 & 32 & $31 / 32(96.88 \%)$ \\
\hline Table 10- Management instructions & 3 & 36 & $18 / 36(50 \%)$ \\
\hline Table 11- Development of support programs & 2 & 8 & $6 / 8(75 \%)$ \\
\hline Table 12- WSP review & 5 & 56 & - \\
\hline Total & 44 & 440 & $222 / 440(50.45 \%)$ \\
\hline
\end{tabular}

to identify strengths and weaknesses. Table 3 shows the overall evaluation of all WSP stages by each stage and the scores earned. Execution percentage in Talesh shows $50.45 \%$ coordination with water safety plan.

Because there is no treatment plant in Talesh, analysis is not possible at this stage and the WSP results for production sources, distribution network, and consumption point are presented in Figures 2-4.

As can be seen in Figure 2, hazard identification and risk assessment with $100 \%$ had the highest score and coordination in implementation with the water safety plan, and because WSP is not fully implemented in Talesh, the steps of improvement plan and review of the WSP have no points.

According to Figure 3, the risk assessment stage (100\%) and hazard identification (90\%) had the highest coordination score with WSP and operational monitoring (43.75\%) had the lowest one.

According to Figure 4, the steps of stakeholders identification and risk assessment (100\%) had the highest implementation coordination with WSP.

Figure 5 shows the third step in WSP, which is related

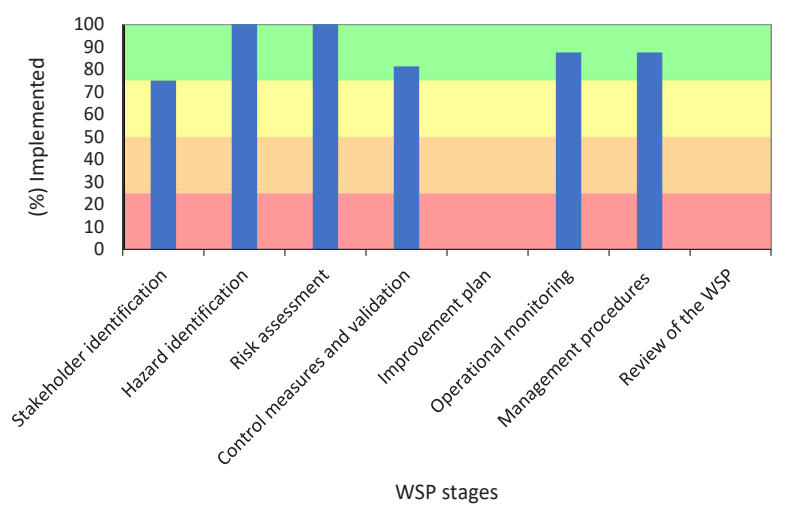

Figure 2. Total assessment of the WSP stages and the results for drinking water supply sources in Talesh city in 2020-2021. to hazard identification and risk assessment. This stage includes 3 parameters of stakeholder identification, hazard identification, and risk assessment. The risk assessment stage has the highest score (80\%). The hazard identification and risk assessment phase obtained 69 points out of a total of 100 raw scores, which indicates $69 \%$ coordination and progress of the third step with WSP.

According to Figure 6, in the water supply system of Talesh city, more attention has been paid to the source of supply and point of consumption than to the distribution network.

One of the most important steps in implementing a water safety program is validation; because the correctness of the program is ensured regularly and accurately. Validation of the three components of compliance monitoring, internal and external audits to confirm operational activities and assess customer satisfaction. All three above-mentioned steps must be performed simultaneously to have effective results in WSP. According to Figure 7 , the audit and handling of consumer complaints with $100 \%$ and validation monitoring with $95 \%$ progress, and according to Table 3, the validation steps were $96.88 \%$ in accordance with WSP.

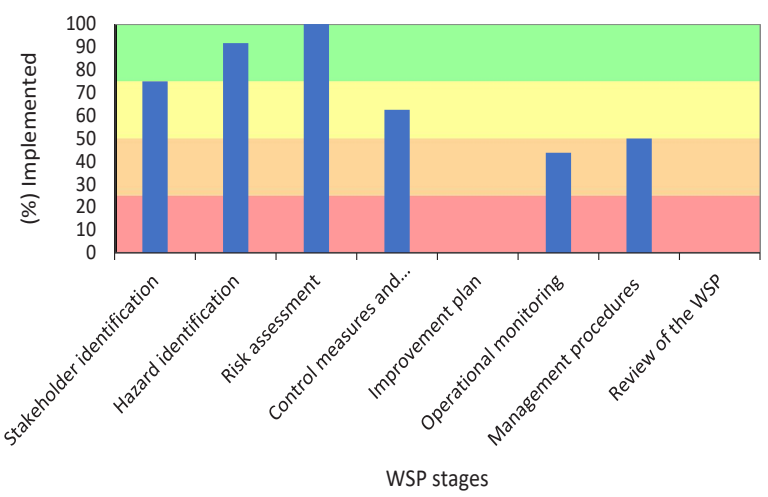

Figure 3. Total assessment of the WSP stages and results for drinking water supply distribution network in Talesh city in 2020-2021. 


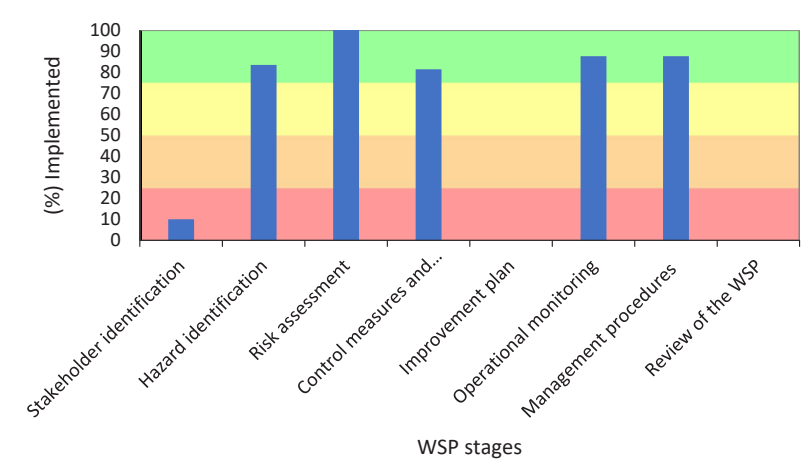

Figure 4. Total assessment of the WSP stages and the results for drinking water consumption points of Talesh city in 2020-2021.

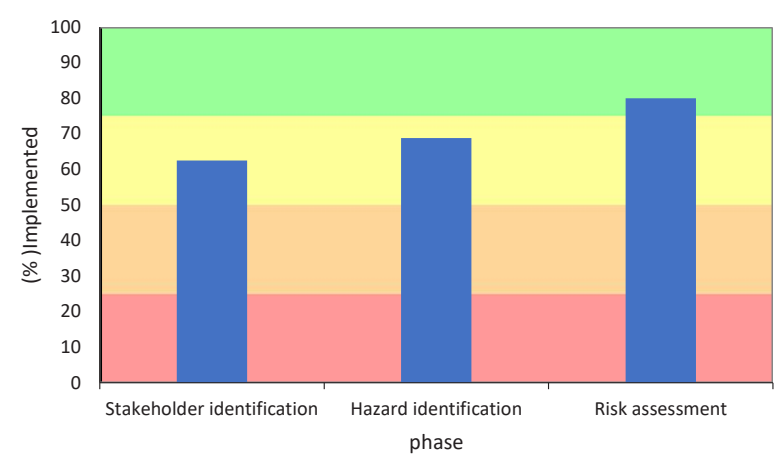

Figure 5. The rate of the WSP implementation in the hazard identification and risk assessment phase of the drinking water supply system of Talesh city in 2020-2021.

\section{Discussion}

The water safety plan provides a systematic approach to ensure the quality of water distributed to consumers. For this purpose, special attention should be paid to the water source, treatment, storage, and distribution of treated water. This plan is based on a general risk assessment that can strongly affect the quality of water distributed to the consumer. Vietnam has implemented a water safety plan in its municipal water supply systems since 2008, and the results of this plan showed an increase in water quality, an increase in customer satisfaction, and a reduction in water-borne diseases (28).

Therefore, in the present study, WSP has been used to identify the risks and potential hazards threatening water safety in the supply system of Talesh. In addition, out of 440 complete score of the program, 336 score were applicable, of which 222 scores were obtained and show $50.45 \%$ compliance with WSP. System description with $100 \%$ and management methods with $50 \%$ showed the highest and lowest compliance with WSP, respectively. A study by Eslami et al, the steps of system description and management procedures obtained the highest and lowest scores with $87.5 \%$ and $25 \%$, respectively, which is consistent with the results of the present study (28).

A study by Baum et al showed that the system description stage is related to drinking water laws in the
United States (29). "Development and improvement plan" and "periodic review" are not evaluable due to the lack of full implementation of WSP in Talesh and are shown without a score. In the study of Aghaei et al, "development and improvement plan" and "periodic review" cannot be evaluated due to the lack of full implementation in Ardabil city, which is consistent with the results of the present study (30). Management procedures are serious, but they are not given much attention here. The guidelines are consisted of standard operating procedure and reformative actions. When there is no remedial action, unexpected events may occur in the water supply systems. These instructions are prepared by skilled personnel and are edited and updated in times of crisis (28).

Talesh water supply system consists of supply sources, transmission lines, distribution network, reservoirs and water consumption point. The scores of each department are $64 \%, 48 \%, 64 \%$, and 154 points out of 352 total points, respectively, which shows the organization's more attention to the source of production and point of consumption. According to the study, the treatment plant and distribution network in France and the water supply source in Spain received the highest attention (27). Due to the high costs of installation and maintenance, less attention is paid to the distribution network of Talesh, and this affects the final quality of water delivered to consumers. In a study by Nijhawan et al on the India Nagpur large pipelines, it was

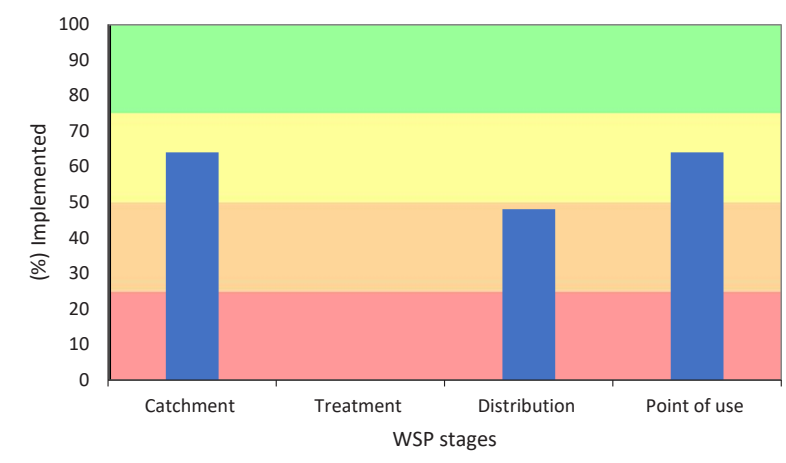

Figure 6. The progress in the overall performance of the WSP stages in the main components of the Talesh water supply system in 2020-2021.

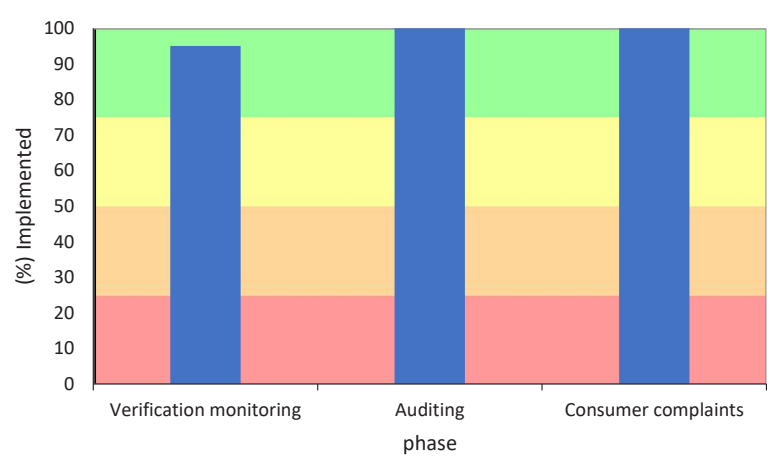

Figure 7. Performance of WSP in the validation phase of the drinking water supply system of Talesh city in 2020-2021. 
revealed that the distribution network was worn out and vulnerable (31).

The various components of the water supply system show that in these four sections, as well as the evaluation of the overall implementation of the plan, some parameters such as "Development of improvement plan" and "WSP review" were not scored due to incomplete implementation of the plan. Identification of hazards at the source, risk assessment at the source, distribution and consumption point have earned full marks, which indicates the consideration of the water organization to identify hazards and risk assessment. A study by Baum et al highlighted the significance of risk assessment and management, which increases confidence in safe drinking water (32). The risk identification and risk assessment stage in the present study obtained 69 points out of a total of 100 raw scores, which indicates $69 \%$ of the implementation progress in WSP. According to the results of a study in Japan, the most important parameter is the hazard identification and risk assessment stage in the water safety plan (33). In a study conducted by Rickert et al, the highest point was obtained for the risk assessment step in accordance with water safety (34).

The validation stage with three parts, validation monitoring with $95 \%$ score and consumer audit and complaint with $100 \%$ and the validation phase score of $96.88 \%$, has the necessary coordination with the water safety plan. The validation stage after the system description has the highest score in Talesh, which shows the importance of controlling the final product in the WSP of Talesh. The main problem of the current approach to water quality management in Talesh is that the supplier organization focuses more on the validation stage and relies on ultimate product tests, and less attention is paid to other stages. In the study of Mortazavi et al, considering the overall advance of the water safety plan in Torbat-e Jam and the special attention of water organization to the control of the final product for integrated management, this plan does not have full and comprehensive efficiency (35).

This study showed that according to the score (50.45\%) of WSP and the attention of water organization to the health of the water produced for the consumer, the system currently has a medium security. The prevailing control approach has the necessary efficiency for the unified management of water supply system in Talesh. The overall assessment of the WSP stages in the Zanjan drinking water supply system showed that $52.95 \%$ have a water safety plan (36).

\section{Conclusion}

In addition to identifying the water supply system needs for upgrading, this study highlights the dependence on the final product test. Due to the effects of WSP on the status of water from the sources of supply to the point of use, the implementation of this program is recommended to water supply organizations as the most efficient tool to ensure security in water supply. In the analysis of drinking water quality in Talesh during the research period, no cases outside the standard were observed.

Therefore, due to the lack of full implementation of the safety plan, there is a possibility of unsanitary accidents. Employees are informed of the dangers of the system, but due to the lack of facilities, it alone cannot hamper incidents. Due to the total use of different stages of WSP, the system has currently a moderate security. Due to the higher score, some steps such as system description, validation, supporting programs, hazard identification, and risk assessment increase the inflexion of the system to change the traditional approach to WSP.

\section{Acknowledgments}

The authors would like to thank the Director of Quality Control of Gilan Water and Wastewater Company and the staff of Talesh Water and Wastewater Company and all those who cooperated in conducting this research.

\section{Ethical issues}

The authors are familiar with the publishing rules and certify that the data obtained during the study are presented in this manuscript and no data from the study has been or will be published elsewhere separately (Ethical code: IR.MUQ.REC.1399.283).

\section{Competing interests}

The authors declare that there is no conflict of interests.

\section{Authors' contributions}

All authors contributed to data collection, analysis, and interpretation, as well as writing the manuscript.

\section{References}

1. Edition F. Guidelines for drinking-water quality. WHO chronicle. 2011;38(4):104-8. https://www.joinforwater. ngo/sites/default/files/library_assets/351_WHO_E13_ guidelines_drinking-water.pdf

2. Rezaei L, Dehghani M, Hassani AH, Alipour V. Seawater reverse osmosis membrane fouling causes in a full scale desalination plant; through the analysis of environmental issues: raw water quality. Environ Health Eng Manag 2020; 7 (2): 119-26. doi: 10.34172/EHEM.2020.14.

3. Rolston A, Linnane S. Drinking water source protection for surface water abstractions: an overview of the group water scheme sector in the Republic of Ireland. Water 2020; 12(9): 2437. doi: 10.3390/w12092437.

4. Yousefi Z, Ala A, Babanezhad E, Ali Mohammadpour R. Evaluation of exposure to phthalate esters through the use of various brands of drinking water bottled in polyethylene terephthalate (PET) containers under different storage conditions. Environ Health Eng Manag 2019; 6(4): 247-55. doi: 10.15171/EHEM.2019.28.

5. Lorestani B, Merrikhpour H, Cheraghi M. Assessment of heavy metals concentration in groundwater and their 
associated health risks near an industrial area. Environ Health Eng Manag 2020; 7(2): 67-77. doi: 10.34172/ EHEM.2020.09.

6. Peletz R, Kumpel E, Bonham M, Rahman Z, Khush R. To what extent is drinking water tested in sub-Saharan Africa? A comparative analysis of regulated water quality monitoring. Int J Environ Res Public Health 2016; 13(3): 275. doi: 10.3390/ijerph13030275.

7. Nikaeen $M$, Shahryari A, Hajiannejad M, Saffari H, Kachuei Moosavian Z, Hassanzadeh A. Assessment of the physicochemical quality of drinking water resources in the central part of Iran. Journal of Environmental Health 2016; 78(6): 40-5.

8. Razmju V, Moeinian K, Rahmani A. Risk assessment of water supply system safety based on WHOs water safety plan: case study Semnan, Iran. Desalination Water Treat 2019; 164: 162-70. doi: 10.5004/dwt.2019.24484.

9. Rahmani A, Nouri J, Kamal Ghadiri S, Mahvi AH, Zare $\mathrm{MR}$. Adsorption of fluoride from water by $\mathrm{Al}^{3+}$ and $\mathrm{Fe}^{3+}$ pretreated natural Iranian zeolites. Int J Environ Res 2010; 4(4): 607-14.

10. Omar YY, Parker A, Smith JA, Pollard SJ. Risk management for drinking water safety in low and middle income countries-cultural influences on water safety plan (WSP) implementation in urban water utilities. Sci Total Environ 2017; 576: 895-906. doi: 10.1016/j.scitotenv.2016.10.131.

11. Herschan J, Rickert B, Mkandawire T, Okurut K, King $\mathrm{R}$, Hughes SJ, et al. Success factors for water safety plan implementation in small drinking water supplies in lowand middle-income countries. Resources 2020; 9(11): 126. doi: 10.3390/resources9110126.

12. Gunnarsdottir MJ, Gardarsson SM, Figueras MJ, Puigdomènech C, Juárez R, Saucedo G, et al. Water safety plan enhancements with improved drinking water quality detection techniques. Sci Total Environ 2020; 698: 134185. doi: 10.1016/j.scitotenv.2019.134185.

13. Davison A, Deere D, Stevens M, Howard G, Bartram J. Water Safety Plan Manual. Geneva, Switzerland: World Health Organization; 2006. p. 3-34.

14. Tavasolifar A, Bina B, Amin MM, Ebrahimi A, Jalali M. Implementation of hazard analysis and critical control points in the drinking water supply system. Int J Environ Health Eng 2012; 1: 32. doi: 10.4103/2277-9183.99334.

15. World Health Organization. Global status report on water safety plans: a review of proactive risk assessment and risk management practices to ensure the safety of drinkingwater. [cited 2020 Jun 12] Available from: https://apps.who. int/iris/handle/10665/255649?locale-attribute=pt \&.

16. Mustapha M, Sridhar M, Coker AO. Assessment of water supply system from catchment to consumers as framed in WHO water safety plans: A study from Maiduguri water treatment plant, North East Nigeria. Sustainable Environment 2021; 7(1): 1901389. doi: 10.1080/27658511.2021.1901389.

17. Kanyesigye C, Marks SJ, Nakanjako J, Kansiime F, Ferrero G. Status of water safety plan development and implementation in Uganda. Int J Environ Res Public Health 2019; 16(21): 4096. doi: 10.3390/ijerph16214096.

18. Pourakbar M, Mosaferi M, Lak S. Assessment of water supply system and water quality of Lighvan village using water safety plan. Environ Health Eng Manag 2015; 2(4): $187-92$.

19. Gholami M, Boodaghi S, Babaloo E. Assessment of water safety plan in Khoy city based on step by step risk management new approach. 14th National Conference on Environ Health; 2011/11/01 Yazd: Shahid Sadoughi University of Medical Sciences;2011.

20. Mosaferi M, Rastgoo S. Program, water safety, the importance of its impact on health. Iran's Sixteenth National Congress on Environmental Health 2013; Iran2013. p. 9.

21. Babaloo E. Assess the safety of drinking water supply in the city of Khoy based on a new approach to management Stepwise risk in 2010. Fourteenth National Conference on Health; 2011/11/01 Yazd: Shahid Sadoughi University of Medical Sciences;2011.

22. World Health Organization. A practical guide to auditing water safety plans. [cited 2020 Nov 12] Available from: https://www.who.int/publications/i/item/9789241509527.

23. World Health Organization. Sanitation Safety Planning: Manual for Safe Use and Disposal of Wastewater Greywater and Excreta: World Health Organization; 2015. https://books.google.com/books?hl=en\&l $\mathrm{r}=\& \mathrm{id}=\mathrm{a} 1 \mathrm{o} 0 \mathrm{DgAAQBAJ} \& \mathrm{oi}=\mathrm{fnd} \& \mathrm{pg}=\mathrm{PP} 1 \& \mathrm{dq}=$ Wor ld + Health + Organization. + Maynilad + Water + Safety + Plan. $+2015 \&$ ots=GFtvLZNsg2\&sig=BFh9yoR-1zAzC BVaN50ianOLfhY\#v=onepage\&q\&f=false

24. Gholami M. Water Safety Program Quality Assurance Tools. In: Sciences ERIoM, editor. Tehran.2013. https://ier. tums.ac.ir/uploads/24/old/_QA_WSP_-correction-_final. pdf

25. World Health Organization, International Water Association. Water safety plan quality assurance tool. [cited 2020 Jun 12] Available from: https://apps.who.int/iris/ handle/10665/78044.

26. Eslami A, Barikbin B, Ghaffari M, Fanaei F. Assessment of Water Safety Plan (WSP) Implementation and Risk Management in Sarayan City. ZANKO 2017; 18(57): 81-95. [In Persian].

27. Masroor K, Kermani M, Gholami M, Fanaei F, Arfaeinia H, Nemati S, et al. Development and implementation of water safety plans for groundwater resources in the southernmost city of West Azerbaijan Province, Iran. J Environ Health Sci Engineer 2020; 8: 629-37. doi: 10.1007/s40201-020-004887.

28. Eslami A, Ghaffari M, Barikbin B, Fanaei F. Assessment of safety in drinking water supply system of Birjand city using World Health Organization's water safety plan. Environ Health Eng Manage 2018; 5(1): 39-47. doi: 10.15171/ EHEM.2018.06.

29. Baum R, Amjad U, Luh J, Bartram J. An examination of the potential added value of water safety plans to the United States national drinking water legislation. Int J Hyg Environ Health 2015; 218(8): 677-85. doi: 10.1016/j. ijheh.2014.12.004.

30. Aghaei M, Nabizade R, Nasseri S, Naddafi K, Mahvi AH, Karimzade S. Risk assessment of water supply system safety based on WHO water safety plan; case study: Ardabil, Iran. Desalination Water Treat 2017; 80: 133-41. doi: 10.5004/ dwt.2017.20889.

31. Nijhawan A, Jain P, Sargaonkar A, Labhasetwar PK. Implementation of water safety plan for a large-piped water supply system. Environ Monit Assess 2014; 186(9): 554760. doi: 10.1007/s10661-014-3802-x.

32. Baum R, Bartram J. A systematic literature review of the enabling environment elements to improve implementation of water safety plans in high-income countries. J Water 
Health 2018; 16(1): 14-24. doi: 10.2166/wh.2017.175.

33. Kunikane S, editor Recent progress in WSP application in Japan. US-Japan Government Conference; Japan 2009. https://www.niph.go.jp/soshiki/suido/pdf/h21JPUS/ abstract/r6-1.pdf

34. Rickert B, van den Berg H, Bekure K, Girma S, de Roda Husman AM. Including aspects of climate change into water safety planning: literature review of global experience and case studies from Ethiopian urban supplies. Int J Hyg Environ Health 2019; 222(5): 744-55. doi: 10.1016/j. ijheh.2019.05.007.
35. Mortazavi M, Shahryari T, Fanaei F, Barikbin B. Safety Assessment of Supply and Distribution Management of Drinking Water in Torbat Jam Using WSP-QA TOOL Software. Journal of Research in Environmental Health 2019; 5(3): 230-8. doi: 10.22038/JREH.2019.41239.1313. [In Persian].

36. Eslami A, Ghafari M, Sohbatloo V, Fanaei F. Safety assessment of Zanjan drinking water System Using water safety plan. Journal of Human Environment and Health Promotion 2017; 2(3): 138-46. 